"This is an Accepted Manuscript of an article published by Taylor \& Francis in JOURNAL OF WOOD CHEMISTRY AND TECHNOLOGY on 12 june 2020, available online:

http://www.tandfonline.com/10.1080/02773813.2020.1772823." 


\section{Elucidating the chemical nature of laccase-modified alkyl gallates}

2 Oriol Cusola ${ }^{1}$, Cristina Valls ${ }^{1}$, Teresa Vidal ${ }^{1}$, M. Blanca Roncero ${ }^{1 *}$

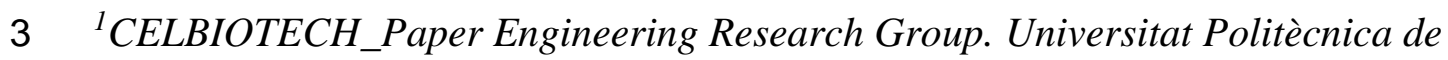

4 Catalunya-BarcelonaTech. Colom 11, E-08222 Terrassa, Spain

5

6 *Corresponding author. Tel.: +34 9373982 10; Fax.: +34 9373981 01. E-mail

7 address: blanca.roncero@ upc.edu (M. Blanca Roncero)

8 


\section{Elucidating the chemical nature of laccase-modified alkyl gallates}

In the first part of the present work, relevant findings concerning the laccase (Lacc) activation of alkyl gallates, and its implementation in developing hydrophobic properties on cellulose-based substrates are reported. Surface state energy by water contact angle (CA), absorption tests, and Cobb 60 measurements were used to assess the hydrophobic behavior of treated substrates. SEM images of paper samples treated with functionalization solutions (FS) revealed the presence of lauryl gallate (LG, dodecyl 3,4,5,-trihydroxybenzoate) particles attached to fibre surfaces. Secondly, the chemical structure of the enzymeoxidized LG and several gallates of variable chain length was elucidated by using Fourier transform infrared (FTIR) spectroscopy, and a plausible oxidation mechanism was developed. Based on them, the hydrocarbon chain of LG remains unaltered after enzyme oxidation, while the aromatic ring is significantly altered to form acidic adducts undergoing strong hydrogen bonding. Possible routes for the grafting of enzyme-modified LG to cellulose are proposed.

Keywords: Laccase; cellulose; alkyl gallates; hydrophobicity; FTIR

\section{Introduction}

Gallic acid and its alkyl esters constitute an important group of biogenic molecules possessing a wide spectrum of interesting properties such as antibacterial $[1,2]$ antioxidant [3-5] antifungal [6], hydrophobic [7] and antitumoral action [8-10]. Some gallic acid derivatives such as methyl, propyl, octyl and dodecyl gallates are widely used in food manufacturing, as well as in the pharmaceutical and cosmetic industries. Most of the properties shown by alkyl gallates are required specifications in materials for packaging or medical uses. Therefore, using alkyl gallates in the production of such materials is indeed an interesting alternative. A number of studies have reported on the use of gallate derivatives to enhance the properties of composites and films, and to 
provide sustained release of antioxidant during storage [11-13].

On the other side, the interest in using biotechnological methods to obtain materials with improved properties has also grown substantially [14-17]. Using enzymes to produce advanced materials has some advantages over chemical methods, allowing to operate under milder conditions, high specificities, efficiency, easy control, and environmental friendliness [18,19]. Laccases (Lacc, EC 1.10.3.2) are blue copper oxidases capable of oxidizing a variety of aromatic compounds by using oxygen as electron acceptor and giving water as by-product.

Laccases provide an eco-friendly approach to improve cellulose properties by means of enzyme-assisted grafting. Their ability to graft low molecular weight phenolic compounds onto cellulose has been demonstrated by several authors [20-23].

Specifically, the laccase-alkyl gallate system was used to confer new properties to composites and cellulose-based materials. For example, Filgueira et al., [24] studied laccase-assisted grafting of octyl gallate and lauryl gallate onto thermomechanical fibers, increasing their compatibility with polymer matrixes in order to achieve biobased 3D printing filaments. Similarly, alkyl gallates with different aliphatic chain length were laccase-grafted onto jute fabric to increase its hydrophobicity and to maximize compatibility in jute/polypropylene composites [16,25,26]. Gaffar et al., [27] studied the laccase-catalysed grafting of various gallates onto wool to obtain multifunctional textile materials with antioxidant, antibacterial and water-repellent properties. Finally, lauryl gallate was used to hydrophobize cellulose fibres [28] and nanofibrillar cellulose [29]. Some authors have inferred the grafting mechanisms, demonstrating that enzyme-activated phenolics stick cellulose through cellulose-bound lignin [30-33]. This requires laccase-assisted activation of fiber surfaces followed by radical coupling. 
All the enzymatic treatments listed above were conducted under the form of aqueous suspensions. This means that fibers, enzyme, and alkyl gallate compounds were present simultaneously in the reaction medium until the end of the treatment, resulting in enzyme-modified fibers. These modified fibers might then be utilized to manufacture products like paper, fabrics or composites, which are expected to show the new functionalities. However, applying treatments on fibrous suspensions may entail several drawbacks, e.g. possible interferences in the interfibre bonding, higher consumption of compounds, or limitations in terms of working conditions $(\mathrm{pH}$, temperature, consistency and reaction time).

A method to circumvent these disadvantages is the two-step process developed in previous works [34-37]. In this new approach, the desired functionalities are achieved upon treatment of finished substrates with a functionalization solution (FS), which is prepared without the presence of any cellulosic material during the reaction. Significant advantages are drawn from this new approach, e.g. it does not affect the binding capacity of the fibers neither the substrate-forming process, it uses reduced amounts of compounds, it has higher effectivity since compounds stay on the surface of the substrates, and it is versatile in terms of the application methods, just to list a few. There is, however, little knowledge about the nature of the chemical changes that laccases endow to alkyl gallates, or the mechanisms by which these enzyme-modified molecules bond to cellulose.

In the present work, these chemical changes are investigated and possible mechanisms by which these molecules graft to cellulose, proposed. First, several data on the ability of enzyme-modified gallates to confer hydrophobic behavior to cellulosebased materials are presented. Commercial and eucalyptus paper sheets were treated with enzyme-modified LG and other gallates and their hydrophobic behavior was 
86 assessed by means of CA, absorption and SEM. Finally, the FTIR findings about the

87 chemical changes undergone by alkyl gallates upon enzymatic reaction are reported.

88 The results allowed establishing various potential mechanisms for the LG-cellulose

89 binding.

\section{$90 \quad$ Materials \& methods}

\section{$91 \quad$ Frequent abbreviations}

92 CA: Contact angle

93 Lacc: Laccase

94 LG: Lauryl gallate, dodecyl 3,4,5-trihydroxybenzoate

95 SL: Sulphonated lignin or lignosulfonates

96 FS: Functionalization solution containing Lacc, LG, and SL

97 FTIR: Fourier-transform infrared

98 GA: Gallic acid, 3,4,5-trihydroxybenzoic acid

99 MG: Methyl gallate, methyl 3,4,5-trihydroxybenzoate

100 EG: Ethyl gallate, ethyl 3,4,5-trihydroxybenzoate

101 PG: Propyl gallate, propyl 3,4,5-trihydroxybenzoate

102 BG: Butyl gallate, butyl 3,4,5-trihydroxybenzoate

103 OG: Octyl gallate, octyl 3,4,5-trihydroxybenzoate

104 SG: Stearyl gallate, octadecyl 3,4,5-trihydroxybenzoate 


\section{Enzyme and chemicals}

106 The enzyme used was laccase (Lacc) from Trametes villosa supplied by Novozymes ${ }^{\circledR}$

107 (Bagsvaerd, Denmark). Gallic acid (GA; $170.12 \mathrm{~g} / \mathrm{mol})$, methyl gallate (MG; 184.15

$108 \mathrm{~g} / \mathrm{mol}$ ), ethyl gallate (EG; $198.17 \mathrm{~g} / \mathrm{mol}$ ), propyl gallate (PG; $212.2 \mathrm{~g} / \mathrm{mol}$ ), butyl gallate

109 (BG; $226.23 \mathrm{~g} / \mathrm{mol}$ ), octyl gallate (OG; $282.33 \mathrm{~g} / \mathrm{mol}$ ), lauryl gallate (LG; $338.44 \mathrm{~g} / \mathrm{mol}$ )

110 and stearyl gallate (SG; $422.606 \mathrm{~g} / \mathrm{mol}$ ) were purchased from Sigma-Aldrich ${ }^{\circledR}$. Soluble

111 sulphonated kraft lignin (SL) was obtained from Borreegard ${ }^{\circledR}$ and used as received.

\section{Preparation of the functionalization solutions (FS)}

113 The enzymatic treatments were performed in an Ahiba Spectradye dyeing apparatus

114 from Datacolor ${ }^{\circledR}$ equipped with closed vessels $250 \mathrm{~mL}$ in volume with final

115 concentrations equivalent to $50 \mathrm{mM}$ sodium tartrate buffer ( $\mathrm{pH}$ 4), gallate compound

$116(1.2 \mathrm{~g} / \mathrm{L})$, lignosulfonate (SL) $(1.2 \mathrm{~g} / \mathrm{L})$, and $1.2 \mathrm{U} / \mathrm{mL}$ laccase. The molar concentration

117 of each gallate compound was: GA, 7.1 mM; MG, 6.5 mM; EG, 6.1 mM; PG, 5.7 mM;

118 BG, $5.3 \mathrm{mM}$; OG, $4.3 \mathrm{mM}$; LG, $3.5 \mathrm{mM}$; and SG, $2.8 \mathrm{mM})$. SL was introduced in the

119 reaction to improve dispersion of the gallate compound. If the gallalte was hydrophobic

120 and no-solubilisation in water was produced, then it was applied as a colloidal

121 suspension prepared upon ultrasonication, achieving a reduction in the effective size and

122 ensuring homogeneous dispersion. Following, the enzyme was added and the beakers

123 were kept stirred during $4 \mathrm{~h}$ reaction. The reaction was stopped by quenching the

124 beakers with cold water. Several control treatments were also performed to elucidate the

125 role of each of the compounds present in the FS.

\section{$126 \quad$ Paper treatment with the FS}

127 Eucalyptus ECF pulp was supplied by $\mathrm{ENCE}^{\circledR}$ (Spain) and used to prepare handsheets on a Rapid-Köten lab former according to ISO 5269-2:2004. Uncoated $67 \mathrm{~g} / \mathrm{m}^{2}$ paper 
was obtained from Torraspape ${ }^{\circledR}$. The obtained solutions (FS), were applied at room temperature to the paper sheets by impregnation/immersion. With this purpose, the paper sheets were cut into circular pieces $4 \mathrm{~cm}$ in diameter and soaked in the FS by keeping the sheet submerged for 3 seconds. Then the paper sheet was removed, spread onto blotting paper, and allowed to dry in a normalized atmosphere $\left(23^{\circ} \mathrm{C}, 50 \% \mathrm{RH}\right)$.

\section{Assessment of the hydrophobic behaviour}

The water contact angle (CA) was measured by using a Dataphysics OCA15EC contact angle goniophotometer using an image capture ratio of 25 frames/s. A $4 \mu \mathrm{L}$ water drop was delivered to the sample surface. At least 10 measurements were made for each liquid probe. Also, changes in contact angle were monitored until complete absorption of each water drop. Cobb 60 absorption tests were performed according to the international standard ISO 535:199.

\section{SEM analysis}

142 Scanning electron microscopy (SEM) was used to examine the surface of paper sheets

143 treated with the functionalization solution (FS) and control solutions. Micrographs were

144 obtained with a JEOL JSM-6400 microscope operating at 5-10 kV under moderate

145 vacuum. Specimens were previously cut into small pieces and coated with a very thin 146 (12 nm) Au-Pd layer on an SCD005 sputter coater to obtain a conductive surface. The 147 particle size of the enzyme-modified LG observed on the paper surface was measured 148 from SEM images using ImageJ software (see supporting information file).

\section{FTIR analysis}

150 For the FTIR analysis of the enzyme-modified LG and other gallates, $200 \mathrm{~mL}$ of the FS 151 was prepared using the doses and reaction conditions explained previously. However, 
152 SL was not introduced in the reaction in order to avoid disturbances coming from this

153 compound in the FTIR analysis. Then, the solutions were centrifuged at $6000 \mathrm{rpm}$

154 during $90 \mathrm{~min}$, and the supernatant eliminated from the sample. Afterwards, the sample

155 was allowed to dry at room temperature until a dry solid residue was obtained, and the

156 solid was placed into a desiccator overnight. Finally, it was finely grinded and mixed

157 with potassium bromide for $\mathrm{KBr}$ pellets preparation. Samples were measured using a

158 Nicolet 6700 FT-IR Spectrometer equipped with spectrum software in the range of $159 \quad 4000-400 \mathrm{~cm}-1$.

160 In the ATR-FTIR experiments with increasing-length gallates, the solid residue 161 was directly analyzed on a Perkin Elmer Spectrum 100 FT-IR spectrometer equipped 162 with universal ATR sampling accessory by performing 32 scans at $1 \mathrm{~cm}-1$ intervals 163 over the wavenumber range $4000-550 \mathrm{~cm}-1$. Pure gallates (i.e. gallates subject to no enzymatic modification) were also analysed. The solid residues were placed directly on the ATR accessory, and the measuring cell was washed with de-ionized water and ethanol between measurements.

\section{Results and discussion}

168 In the first part of this work, previous and current efforts on the use of LG and other 169 alkyl gallates to achieve the enzymatic functionalization of cellulosic substrates are 170 outlined. In the second part, FTIR studies undertaken to elucidate the chemical nature of enzyme-modified alkyl gallates, with a particular emphasis on LG compound are reported.

\section{Enzymatic modification of alkyl gallates and substrate treatments}

175 highly hydrophobic, and tends to aggregate (i.e., accumulate and clump together). 
176 Therefore, LG dispersion was a key aspect to optimize the action of the enzyme. Thus,

177 sulfonated lignins (SL) were added, significantly increasing dispersion, among other

178 benefits [34,36]. The best performance was observed when reaction (Laccase-LG), was

179 conducted under the presence of SL, resulting in a three-compound reaction mixture

180 named functionalization solution (FS). This resulting product (FS) was able to increase

181 the hydrophobic behaviour of cellulose-based materials after impregnation and drying

182 (Figure 1a). As shown in Figure 1b, the water contact angle and Cobb $_{60}$ values significantly increased upon treatment with FS. The treatment with FS is able not only to modify the surface state energy, but also the water absorption of the material, as depicted in Figure 1c.

The Lacc, LG and SL dose and reaction time to achieve the FS were selected according to previous studies. Further experiences to assess the influence of LG and SL dosing (see Table S1 and Figure S1 in the supporting information file) were performed. The results showed that short reaction times (between 1 and 2 hours) were not effective in developing the hydrophobic property, either by using low or high doses. Possibly, enzyme was not able to complete oxidation in the time interval considered. For long reaction periods (between 2 and 4 hours), the use of lower concentrations seemed to be more effective in the development of the hydrophobic property. The highest hydrophobic level was attained when using $1.2 \mathrm{~g} / \mathrm{L}$ for $\mathrm{LG}$ and $\mathrm{SL}$ and $1.2 \mathrm{U} / \mathrm{mL}$ of enzyme, with a reaction time of $3 \mathrm{~h}$. The use of very high doses (x20) with either long or short reaction time is deleterious as to enzymatic modification. 1d, an increased hydrophobic behaviour was observed after treatment with functionalization solutions prepared with increasing-chain-length gallates. However, very long gallates (longer than LG), namely Stearyl Gallate, (with 18 carbons in the 
chain), are deleterious as far as the hydrophobic property. The reason was the

202 impossibility to disperse this compound in aqueous medium, due to its very high hydrophobic nature and very low solubility.

204

205

206

207

208

209

210

211

212

213

214

215

216

217

218

219

220

221

222

223

\section{SEM analysis of cellulosic material treated with FS}

The surface of cellulose and FS-treated cellulose specimens was examined by scanning electron microscopy (SEM, Figure 2). Figures $2 \mathrm{a}$ and $2 \mathrm{~b}$ show the surface of nontreated cellulose, where smooth and clean fibres are appreciated. By contrast, treatment with FS (Figures 2c and 2d) caused significant morphological changes in the fibres. Thus, after the treatment with FS, small nanosized particles (90 to $600 \mathrm{~nm}$ ) appeared on the surface (See Figure S3 in supporting information file). Such particles consisted of enzyme-modified LG, and contributed to the hydrophobic behaviour of the paper sheets. The particles are barely distinguishable in the macroscopic image of FS-treated paper (Figure 2c) —only a few of the larger ones can clearly be seen-, but apparent in the magnified view of the surface in Figure 2d. Worth special note is the wide range of LG particle sizes present in the image (aggregates from 100 to more than $500 \mathrm{~nm}$ in size), and so is the fact that gold-sputtering the fibre surfaces — a requirement for SEM analysis of non-conductive materials such as cellulose - coated the sample with a thin (10-30 nm) layer of gold, which may have completely covered small LG particles and hidden them from view.

Paper sheets were also impregnated with several control treatments to elucidate the effect of each individual compound in the FS, and combinations thereof (Figure S2). Only the treatments in which LG was present caused deposition of LG particles onto fibre surfaces. Although LG and LG+Lacc treatments produced similar effect (as far as the SEM images), a significant difference in terms of attachment of LG particles was apparent. Thus, the specimen treated with the LG control consisted of LG-deposited 
particles whereas that treated with Lacc+LG contained firmly attached particles on the

227 fibre surface, consistent with the previously found results [37]. Unlike the surface particles of the Lacc+LG treatment, those resulting from the LG treatment were easily removed by washing with water. The effects of the enzyme were thus quite clear: altering the chemical nature of LG and facilitating its anchoring onto fibre surfaces.

231

232

233

234

235

236

237

238

239

240

241

242

243

244

245

\section{FTIR analysis of pure and enzyme-modified LG}

Figure 3 shows the FTIR absorbance spectra for LG before and after oxidation by the enzyme (LG+Lacc). The overall shape of the spectrum for LG changed upon enzymatic modification; thus, the initial LG spectrum contained a number of strong, well-defined peaks, whereas in that for enzyme-treated LG, some peaks disappeared or shifted wavenumber.

The peaks at 2848 and $2916 \mathrm{~cm}^{-1}$ corresponded to methylene and methyl groups in the pure LG hydrocarbon chain. As shown, these peaks remained unchanged upon enzymatic modification of LG, indicating that enzyme oxidation probably did not alter the hydrocarbon chain. The adsorption band at $1668 \mathrm{~cm}^{-1}$ for unmodified LG must correspond to $\mathrm{C}=\mathrm{O}$ stretching in the ester — which usually appears at higher wavenumbers in esters. The reason for this shift may be due to the connection of the ester with the aromatic ring (an aryl ester) [38], and also to hydrogen bonding interactions of the ester with hydroxyl groups in the same molecule (intra-molecular interactions) or in others (inter-molecular interactions) [39] (See Figure S4 in supporting information file). Intra-molecular interactions should be independent of the gallate chain length; in fact, the $\mathrm{C}=\mathrm{O}$ stretching band for the ester group in other gallates appeared at the expected frequencies, as it will be discussed in the next sections.

A longer chain may thus prevent inter-molecular interactions but promote intramolecular interactions. 
The carbonyl peak appeared at higher frequencies in the spectrum for enzyme-

252 modified LG $\left(1718 \mathrm{~cm}^{-1}\right)$. Since the action of the enzyme focuses on the phenol [40], the shift may be a result of some alteration of the aromatic ring such as cleavage and the formation of a carboxylic acids [41], whose peaks usually appear in a very specific frequency range $\left(1725-1700 \mathrm{~cm}^{-1}\right)$. The ester peak did not disappear and, probably, the ester and carboxylic acid peaks merged at $1718 \mathrm{~cm}^{-1}$. Further evidence of ring opening/alteration or also quinone formation was obtained from the LG peaks observed in the $1600-1450 \mathrm{~cm}^{-1}$ range, which correspond to $\mathrm{C}=\mathrm{C}-\mathrm{C}$ aromatic ring bonds. Such peaks were considerably different in the enzyme-modified LG spectrum (specifically, the peak at $1533 \mathrm{~nm}$ disappeared altogether).

Stretching vibrations of the hydroxyl group in the unmodified LG molecule reflected in a broad band in the range $3600-3300 \mathrm{~cm}^{-1}$ containing peaks at $3450-3348$ $\mathrm{cm}^{-1}$. There were no strong peaks for unbounded hydroxyl groups in the range 3645$3600 \mathrm{~cm}^{-1}$; rather, the broad band at $3600-3300 \mathrm{~cm}^{-1}$ is suggestive of $\mathrm{H}$-bonding of hydroxyl groups in the same (intra-molecular hydrogen bonding) or neighboring molecules (inter-molecular bonding). The reduction and further broadening of this band observed in enzyme-modified LG was also an indication of the disappearance of hydroxyl groups and formation of carboxyl groups; a highly characteristic large shift to lower frequencies by effect of carboxyl groups establishing extremely strong hydrogen bonds was observed.

The reaction mechanism for the oxidation of gallic acid proposed by Tulyathan et al., [42], in combination with our FTIR results, can be used to understand the nature of the LG oxidation mechanism caused by laccase. Laccases exhibit specificity for phenols, diphenols, aryldiamines, aminophenols, benzenethiols and hydroxyindoles; this was confirmed by FTIR, which exposed major changes in the wavenumbers 
corresponding to the aromatic ring but none in those for the hydrocarbon chain. Also,

277

278

279

280

281

282

283

284

285

286

287

288

289

290

291

292

293

294

295

296

297

298

299

300

the hypothesis is based on the reported bacterial degradation pathway for phenylacetate, which represents an example of cleavage of an aromatic compound while retaining an ester bond [43-45]. The LG oxidation mechanism proposed here involves the following steps (Figure 4): (1) Laccase catalyses the oxidation of LG by removing electrons and hydrogen ions from phenolic hydroxyl groups to produce phenoxy radicals [40] (2) which are further oxidized to quinones (3), thereby causing cleavage of the aromatic ring and producing hydrophilic carboxyl groups in the form of muconic acid derivatives $[46,47](4)$. The next step is pictured as alternative pathways that account for condensation of hydroxyl groups in the alcohol and carboxyl groups $(-\mathrm{COOH})$ to form a lactone [48] (5) or decarboxylation and further oxidation $(6,7)$. According to some authors, laccase-mediator systems can form activated oxygen species such as hydroxyl radical $\left(\mathrm{HO}^{\circ}\right)$ and superoxide anion radical $\left(\mathrm{O}^{\circ}{ }^{*}\right)$ [49]. Such radicals can also boost oxidation of the $\mathrm{LG}$ product by breaking $\mathrm{C}-\mathrm{C}$ bonds and causing cleavage of aromatic rings and scission of conjugated double bonds as a result [50].

Formation of stable dimers by regeneration of hydroquinones (after step 3) might be difficult due to steric hindrances caused by the long hydrocarbon chain of LG. As proposed by Tulyathan et al., [42] for the oxidation of gallic acid, the reaction must lie between the formation of single-molecule open-ring acidic products or oxidation of a dimer to acidic products. We hypothesize that the laccase reaction produces single LG molecules with open-ring acid moieties anchored to the alkyl chain via the original ester (Figure 4). The strong anionic character of such molecules seems to be the main agent enhancing retention on cationic surfaces.

The dark color of the Lacc-LG reaction products is ascribed to the formation of quinone structures as in step (3) of Figure 4. However, such color decreased as the 
reaction developed, suggesting that further oxidation increased the likelihood of

302 obtaining larger amounts of the colorless molecule formed in step (7) of Figure 4, and hence lighter colored reaction product.

The formation of polymerized species of LG, such as dimers or trimers, might be limited by the above-described potential steric hindrances, and confirmed by the decreased turbidity, as observed in previous works. Dynamic light scattering and turbidity measurements showed LG particle size to be decreased by effect of the enzyme (viz. by its reducing the turbidity of the reaction product as assessed with a Turbiscan $^{\circledR}$ ) [37]; such an effect was present after long treatment —as long as some enzymatic activity remained. These results suggested clarification of the solution by

311 effect of particle size reduction and quinone destruction, and formation of none of the above-mentioned condensation adducts. S4 in supporting information file).

\section{FTIR-ATR analysis of gallates with increasing chain length and the effect of}

\section{7 the enzymatic modification}

318 The FTIR study was extended to other compounds of the gallate family in order to

319 strengthen our understanding of the relationship between the gallates' structure and their chemical enzymatic changes. Each gallate was laccase-oxidized under the reaction conditions described, albeit in the absence of SL in order to avoid disturbances coming from the presence of this compound (as explained in the materials \& methods section) The obtained products were concentrated and dried. The resulting powders consisting of enzymatically-modified gallates, and pure gallates as well, were assessed by FTIR- 
gallates (Figure 5b) over the wavenumber range $3600-2600 \mathrm{~cm}^{-1}$; Figures $5 \mathrm{c}$ and $5 \mathrm{~d}$

327

328

329

330

331

332

333

334

335

336

337

338

339

340

341

342

343

344

345

346

347

348

349

350 show those in the spectral region from 1750 to $600 \mathrm{~cm}^{-1}$.

Based on Figures $5 \mathrm{a}$ and $5 \mathrm{~b}$, the hydrocarbon chains remained intact after reaction with the enzyme; the peaks for methyl $\left(-\mathrm{CH} 3,2850 \mathrm{~cm}^{-1}\right)$ and methylene groups $\left(-\mathrm{CH} 2,2916 \mathrm{~cm}^{-1}\right)$ remained unchanged. This was particularly so for the longchain gallates and, especially, for PG and longer gallates. The enzyme caused no chemical changes in the alkyl chain. The peaks for $-\mathrm{CH} 2$ and $-\mathrm{CH} 3$ groups in the hydrocarbon chain increased intensity with increasing chain length; this was especially so for methylene groups, by effect of their increase in number with increasing chain length.

The broad band from 3570 to $3200 \mathrm{~cm}^{-1}$ for the pure gallates (Figure 5a) corresponds to the hydroxyl groups in their phenol moiety. The large width of the band was due to intra- and inter-molecular hydrogen bonding interactions typical of such groups [38]. The band was very similar in shape and strength for all pure gallates, since they contain identical number of hydroxyl groups. However, reaction with the enzyme decreased this band due to disappearance of such groups, and made it even broader, possibly by an increased number of hydrogen-bonding interactions in the remaining groups. This latter finding was evident for all compounds. Enzyme modification may have caused the formation of carboxyl groups (as explained in the previous section); hydroxyl functions in carboxyl groups typically establish strong hydrogen bonds (noticeable by the shift of the band to lower frequencies).

The carbonyl group in pure gallates (Figure 5c) absorbed at different frequencies (see table 1). In pure GA, the carbonyl peak in the acidic group appeared at $1700 \mathrm{~cm}^{-1}$, as described elsewhere. Besides MG, the carbonyl peak in the gallates shifted to gradually-decreasing wavenumbers. Specific substituents may cause variations in 
absorption frequencies, producing the expansion of carbonyl $(\mathrm{C}=\mathrm{O})$ stretch region.

352 Thus, the stretch of conjugated $\mathrm{C}=\mathrm{O}$ (as in gallates), lie at lower wavenumbers. This conjugation combined with the possible hydrogen-bonding interactions may have reduced the stretch frequency of the $\mathrm{C}=\mathrm{O}$ groups. Results suggest that longer alkyl chains tend to decrease the vibrational frequency of the $\mathrm{C}=\mathrm{O}$ group, possibly by the increased probability of interaction of this group with a larger number of hydrogen atoms in the chains, leading to the weakening of the bond vibration. identical in shape and strength before and after reaction. This suggests that SG was not or slightly modified by the enzyme. In fact, the reaction product exhibited no color, which suggested that modification was not taking place. This is in contrast to what is observed for the other gallates, in which the resulting o-quinones upon enzymatic reaction usually undergo side reactions, either between one another or with other substances in their immediate vicinity, to form a variety of colored compounds [51-53]. Possibly, the long hydrocarbon chain of the SG molecule may have prevented the phenol moiety from accessing the catalytic site of the enzyme, thereby inhibiting its oxidation due to steric hindrance. In fact, some authors have suggested that the rate of oxidation of gallates by the enzyme tyrosinase decreases with increasing alkyl chain length of the substrate [54]. In the present work, similar effects were observed with laccase.

372 disappear. Longer gallates (PG, BG, OG and LG), exhibited the peak at the same 373 frequency $\left(1714 \mathrm{~cm}^{-1}\right)$, except in SG, which has not been modified. Therefore, the enzyme may have induced similar chemical changes in PG, BG, OG and LG. All pure gallates exhibited three well-defined peaks at the same vibrational frequencies in the 
range $1615-1450 \mathrm{~cm}^{-1}$, corresponding to $\mathrm{C}=\mathrm{C}-\mathrm{C}$ vibrations in the aromatic ring (Figure

377 5c). The central peak $\left(1540-1520 \mathrm{~cm}^{-1}\right)$ disappeared upon reaction with the enzyme

378 (Figure 5d) and thus reflected the changes undergone by the aromatic ring. The peak at

$3791200 \mathrm{~cm}^{-1}$ in pure gallates (Figure 5c) might correspond to vibration of phenolic $\mathrm{C}-\mathrm{OH}$

380 bonds, since all compounds exhibited one. Enzymatic modification caused the peak to

381 disappear from the spectra for some (GA, MG, EG) and may be masked by the broad

382 band at higher frequencies (about $1225 \mathrm{~cm}^{-1}$ ) for others (PG, BG, OG and LG) (Figure $3835 d)$.

384

385

386

387

388

389

390

391

392

393

394

395

396

397

398

\section{Proposed mechanisms for the bonding of enzyme-modified LG to cellulose}

As explained in the first part of the present work, interactions between enzymemodified LG and cellulosic materials increase their hydrophobic properties. As revealed by FTIR observations, the enzyme-modified LG molecule possesses a hydrophilic head with acidic moieties, and a hydrophobic alkyl chain. The open-ring carboxyl groups (Figure 4) confer enzyme-modified LG a strong anionic character; this is the main aspect which facilitates the retention of such molecules onto cationic cellulosic materials, as observed in previous works.

Based on previous considerations on paper sizing [55], effective hydrophobization of cellulosic materials with LG requires i. the hydrophilic head of LG to be oriented towards the fibres, and the hydrophobic tail outwards; ii. LG to be evenly distributed throughout the material; and iii. optimal spacing between LG molecules on the fibres, allowing an efficient water-repellent character. Since the most likely scenario for enzyme-modified LG is one where all the molecules in Figure 4 coexist, we propose several mechanisms for the grafting of enzymatically treated LG to cellulosic materials. 
400 As found in previous studies [37], a significant increase in hydrophobic behaviour was 401 obtained with cationic substrates, produced with compounds such as polyamidoamine402 epichlorohydrin, cationic starch, or methyl glycol chitosan before treatment with enzyme-modified LG. The strong anionic character of enzyme-modified LG conferred by its carboxyl groups would facilitate interaction with the cationic groups in cellulose, and hence its functionalization (see Figure 6a).

\section{Mechanism 2. Esterification reactions}

407 The oxidized LG obtained in step (7) of Figure 4 would react with cellulose and water

408 by esterification as depicted in Figure 6b. In our previous study [34] we found that heat 409 treatments increase hydrophobicity; this effect can be ascribed to the removal of water,

410 which is therefore essential to promote the esterification reactions. Under drying 411 conditions, an ester may form between carboxyl groups in LG and hydroxyl groups in 412 cellulose surfaces. Oxidized LG could even form a highly reactive cyclic anhydride 413 (Figure 6b) which would facilitate grafting without heat treatment via a reaction mechanism similar to that for alkenyl succinic anhydrides (ASAs) used as sizing agents 415 for cellulosic materials [56,57]. Minimizing hydrolysis of the enzyme-modified LG molecule to promote the grafting reactions entails efficiently removing water in the

417 medium by drying. Oxidized LG moieties may attach to cellulose surfaces via Fischer's

418 esterification reaction between hydroxyl surface groups in cellulose and carboxyl

419 groups in enzyme-modified LG. In this mechanism, the sodium tartrate buffer used in 420 the enzymatic reaction, which derives from tartaric acid, would act as a strong acid 421 catalyst for the reaction promoting protonation of carboxyl groups (a reversible 422 reaction); the composition of the reaction mixture or equilibrium position would be 
thermodynamically governed. Obtaining the ester in good yields would require efficient removal of water by drying. In fact, the presence or addition of water here is of some concern as the water can shift the reaction equilibrium away from the ester formation and towards the carboxylic acid. appropriate orientation — which, as noted earlier, is a prerequisite for the development of hydrophobic effect.

\section{Mechanism 3. Ring-opening grafting reactions}

The reactions induced via lactone ring-opening involve a monomer, an initiator and a catalytic system. Since an alcohol (or hydroxyl group) is generally used as initiator, cellulose in its native form acts as a multifunctional trigger for the modification of cellulose or cellulose derivatives [58]. The cyclic product obtained in step (5) of Figure 4 is a lactone that could be grafted to cellulose via a ring-opening mechanism similar to the one shown for $\varepsilon$-caprolactones and lactic acids elsewhere [59-61].

In the grafting of cellulose using the conventional ring-opening polymerization a metal catalyst (usually stannous 2-ethylhexanoate, SnOct2) is commonly used; this makes the resulting cellulose products useless for biomedical and food packaging applications, and promoted the use of alternative, non-toxic organocatalysts since 2001 [62-64]. For example, Hafrén and Córdova [65] reported on the surface-initiated

442 grafting of $\varepsilon$-caprolactone from a cellulose substrate using tartaric acid as catalyst.

443 Remarkably, in the current work the buffer solution used to obtain the enzyme-modified 444 LG was prepared from tartaric acid. Thus, the lactone formed in step (5) of Figure 4 445 could be grafted via ring-opening onto the cellulosic material under heating conditions, 446 following similar mechanisms to those reported by Hafrén and Córdova. Heating is 447 required for efficient grafting of lactones onto cellulosic materials; as shown in previous 
works [36], heat treatments boosted grafting of enzyme-modified LG onto cellulose.

449 Figure $6 \mathrm{c}$ depicts the proposed mechanism for the surface grafting via lactone ring-

450 opening. The mechanism differs from that reported elsewhere for the ring opening

451 polymerization of $\varepsilon$-caprolactone in that there's no actual polymerization after the initial

452 grafting, since there are no active ends in the grafted molecule.

\section{Conclusions}

454 The treatment of cellulosic substrates with enzyme-modified LG and other gallates

455 produced a significant improvement in the water contact angle and Cobb $_{60}$ values. In

456 addition, the water absorption of the material was significantly reduced, evidencing a

457 strong hydrophobic behaviour. The SEM images of paper specimens treated with FS

458 revealed the presence of LG particles attached to the fibres. An exhaustive FTIR

459 analysis revealed that enzyme-modified LG consists mainly of open-ring acidic

460 products, which may undergo further oxidation via various pathways. Strong H-bonding

461 interactions were observed in the resulting molecules. By contrast, the hydrocarbon

462 chain of LG remained unaltered. FTIR-ATR analysis of enzyme-modified gallate-

463 family-compounds also revealed that their alkyl chain was unaltered upon enzymatic

464 modification, while major changes were observed in the peaks of their phenolic

465 moieties. Stretching vibrations in the carbonyl and hydroxyl groups were considerably

466 altered by effect of H-bonding interactions in all pure and modified gallates. A plausible

467 oxidation mechanism was developed for LG, and several alternatives for the grafting of

468 such molecules to cellulose-based materials were proposed.

\section{Acknowledgements}

470 The authors are grateful to the FILMBIOCEL (No. CTQ2016-77936-R) (funding also

471 from the "Fondo Europeo de Desarrollo Regional FEDER"), and MICROBIOCEL (No. 
472 CTQ2017-84966-C2-1-R), within the framework of the Spanish's MINECO. Special

473 thanks are also due to the Serra Húnter Fellowship awarded to C.Valls and O. Cusola.

\section{Supporting information}

475 Time/concentration influence on hydrophobicity of FS-treated sheets (Table S1 and 476 Figure S1); SEM analysis of FS control products (Figure S2); Particle size

477 measurements using ImageJ software (Figure S3); Hydrogen-bond interactions of pure 478 and enzyme-modified LG (Figure S4 and S5).

\section{References}

480 [1] A. Elmi, R. Spina, F. Abdoul-Latif, S. Yagi, S. Fontanay, A. Risler, R.E. Duval, D. Laurain-Mattar, Rapid screening for bioactive natural compounds in Indigofera caerulea Rox fruits, Ind. Crops Prod. $125 \quad$ (2018) 123-130. doi:10.1016/j.indcrop.2018.08.089.

[2] I.C. Silva, L.O. Regasini, M.S. Petrãnio, D.H.S. Silva, V.S. Bolzani, J. Belasque, L.V.S. Sacramento, H. Ferreira, Antibacterial activity of alkyl gallates against Xanthomonas citri subsp. citri, J. Bacteriol. $195 \quad$ (2013) 85-94. http://www.scopus.com/inward/record.url?eid=2-s2.084872042524\&partnerID=40\&md5=b085a48d5ee665cb9b8a1e5fbe56440e

[3] I. Ferreira, M. Costa, S. Losada-Barreiro, F. Paiva-Martins, C. Bravo-Díaz, Modulating the interfacial concentration of gallates to improve the oxidative stability of fish oil-in-water emulsions, Food Res. Int. 112 (2018) 192-198. doi:10.1016/j.foodres.2018.06.007.

[4] J. Freiría-Gándara, S. Losada-Barreiro, F. Paiva-Martins, C. Bravo-Díaz, Enhancement of the antioxidant efficiency of gallic acid derivatives in intact fish oil-in-water emulsions through optimization of their interfacial concentrations, 
Food Funct. 9 (2018) 4429-4442. doi:10.1039/c8fo00977e.

497 [5] I. Kubo, N. Masuoka, T.J. Ha, K. Shimizu, K. Nihei, Multifunctional antioxidant 498 activities of alkyl gallates, Open Bioact. Compd. J. 3 (2010) 1-11. http://www.scopus.com/inward/record.url?eid=2-s2.077953455602\&partnerID=40\&md5=a67804d4c1be627657c0cf2bb953b846.

501

[6] F.L. Hsu, P.S. Chen, H.T. Chang, S.T. Chang, Effects of alkyl chain length of 502 gallates on their antifungal property and potency as an environmentally benign 503

504

505

506

507

508

509

[8] preservative against wood-decay fungi, Int. Biodeterior. Biodegrad. 63 (2009) $543-547$. http://www.scopus.com/inward/record.url?eid=2-s2.067349095614\&partnerID=40\&md5=cb2d87ff0712d48833e81e2fb29bff27.

[7] E. Takai, A. Hirano, K. Shiraki, Effects of alkyl chain length of gallate on selfassociation and membrane binding, J. Biochem. 150 (2011) 165-171. doi:10.1093/jb/mvr048.

510

511

512 1119-1127. doi:10.21873/invivo.11354.

513

E. Ortega, M.C. Sadaba, A.I. Ortiz,

C. Cespon, A. Rocamora, J.M. Escolano, G. Roy, L.M. Villar, P. Gonzalez-Porque, Tumoricidal activity of lauryl gallate towards chemically induced skin tumours in mice, Br. J. Cancer. 88 (2003) 940943. http://www.scopus.com/inward/record.url?eid=2-s2.00037464298\&partnerID=40\&md5=bd3eaad75005fb214693e4c3e4f02f45.

[10] A. Serrano, C. Palacios, G. Roy, C. Cespón, M.L. Villar, M. Nocito, P. González519 Porqué, Derivatives of gallic acid induce apoptosis in tumoral cell lines and inhibit lymphocyte proliferation, Arch. Biochem. Biophys. 350 (1998) 49-54. 
http://www.scopus.com/inward/record.url?eid=2-s2.0$0031874555 \&$ partnerID=40\&md5=97394e6004f60f611d43e4f6c 7263575.

523

524

525

526

527

528

529

530

531

532

533

534

535

536

537

538

539

540

541

542

543

544

545

[11] K. Limpisophon, G. Schleining, Use of Gallic Acid to Enhance the Antioxidant and Mechanical Properties of Active Fish Gelatin Film, J. Food Sci. 82 (2017) 8089. doi:10.1111/1750-3841.13578.

[12] F. Luzi, D. Puglia, F. Dominici, L. Torre, Influence of gallic acid and umbelliferone on structural and functional properties of poly(vinyl alcohol-coethylene) films for food packaging, in: AIP Conf. Proc., 2018. doi:10.1063/1.5045952.

[13] D. Alkan, L.Y. Aydemir, I. Arcan, H. Yavuzdurmaz, H.I. Atabay, C. Ceylan, A. Yemenicioğlu, Development of flexible antimicrobial packaging materials against Campylobacter jejuni by incorporation of gallic acid into zein-based films, J. Agric. Food Chem. 59 (2011) 11003-11010. doi:10.1021/jf202584b.

[14] S. Kalia, K. Thakur, A. Kumar, A. Celli, Laccase-assisted surface functionalization of lignocellulosics, J. Mol. Catal. B Enzym. 102 (2014) 48-58. doi:10.1016/j.molcatb.2014.01.014.

[15] N. Liu, S. Ni, A.J. Ragauskas, X. Meng, N. Hao, Y. Fu, Laccase-mediated functionalization of chitosan with 4-hexyloxyphenol enhances antioxidant and hydrophobic properties of copolymer, J. Biotechnol. 269 (2018) 8-15. doi:10.1016/j.jbiotec.2018.01.015.

[16] R. Liu, A. Dong, X. Fan, Y. Yu, J. Yuan, P. Wang, Q. Wang, A. Cavaco-Paulo, Enzymatic Hydrophobic Modification of Jute Fibers via Grafting to Reinforce Composites, Appl. Biochem. Biotechnol. $178 \quad$ (2016) 1612-1629. doi:10.1007/s12010-015-1971-x.

[17] A. Aljawish, I. Chevalot, B. Piffaut, C. Rondeau-Mouro, M. Girardin, J. 
Jasniewski, J. Scher, L. Muniglia, Functionalization of chitosan by laccasecatalyzed oxidation of ferulic acid and ethyl ferulate under heterogeneous reaction

548

549

550

551

552

553

554

555

556

557

558

559

560

561

562

563

564

565

566

567

568

569

570

conditions, Carbohydr. Polym. $87 \quad$ (2012) 537-544. doi:10.1016/j.carbpol.2011.08.016.

[18] P.B. Skals, A. Krabek, P.H. Nielsen, H. Wenzel, Environmental assessment of enzyme assisted processing in pulp and paper industry, Int. J. Life Cycle Assess. 13 (2008) 124-132. http://www.scopus.com/inward/record.url?eid=2-s2.045349085677\&partnerID=40\&md5=9b19109367ccd5998dec41ecfc3766fc.

[19] O. Kirk, T.V. Borchert, C.C. Fuglsang, Industrial enzyme applications, Curr. Opin. Biotechnol. 13 (2002) 345-351. doi:10.1016/S0958-1669(02)00328-2.

[20] E. Aracri, M.B. Roncero, T. Vidal, Studying the effects of laccase-catalysed grafting of ferulic acid on sisal pulp fibers, Bioresour. Technol. 102 (2011) 75557560. http://www.scopus.com/inward/record.url?eid=2-s2.079959601090\&partnerID=40\&md5=334e0e840032a97b30d544a49f8f5c11.

[21] E. Aracri, A. Fillat, J.F. Colom, A. Gutiérrez, J.C. Del Río, A.T. Martínez, T. Vidal, Enzymatic grafting of simple phenols on flax and sisal pulp fibres using laccases., Bioresour. Technol. 101 (2010) 8211-6. doi:10.1016/j.biortech.2010.05.080.

[22] E.M. Cadena, X. Du, G. Gellerstedt, J. Li, A. Fillat, J. Garcia-Ubasart, T. Vidal, J.F. Colom, On hexenuronic acid (HexA) removal and mediator coupling to pulp fiber in the laccase/mediator treatment., Sect. Title Cellul. Lignin, Pap. Other Wood Prod. 102 (2011) 3911-3917.

[23] A. Fillat, O. Gallardo, T. Vidal, F.I.J. Pastor, P. Díaz, M.B. Roncero, Enzymatic grafting of natural phenols to flax fibres: Development of antimicrobial properties, Carbohydr. Polym. 87 (2012) 146-152. http://www.scopus.com/inward/record.url?eid=2-s2.0- 
572 [24] D. Filgueira, S. Holmen, J.K. Melbø, D. Moldes, A.T. Echtermeyer, G. Chinga573 Carrasco, 3D printable filaments made of biobased polyethylene biocomposites, 574 Polymers (Basel). 10 (2018). doi:10.3390/polym10030314.

575

[25] C. Zhou, Q. Wang, Y. Yu, X. Fan, Y. Cao, T. Li, Functional modification of jute fiber by enzymatic grafting of gallate esters, Chem. Eng. Trans. 62 (2017) 193198. doi:10.3303/CET1762033.

[26] X. Ni, A. Dong, X. Fan, Q. Wang, Y. Yu, A. Cavaco-Paulo, Jute/polypropylene composites: Effect of enzymatic modification on thermo-mechanical and dynamic mechanical properties, Fibers Polym. 16 (2015) 2276-2283. doi:10.1007/s12221015-5475-7.

[27] K.M.G. Hossain, M. Díaz-González, J.M.D. Monmany, T. Tzanov, Effects of alkyl chain lengths of gallates upon enzymatic wool functionalisation, J. Mol. Catal. B Enzym. 67 (2010) 231-235. http://www.scopus.com/inward/record.url?eid=2s2.078049264740\&partnerID=40\&md5=61083613110229661f1545803c808419.

[28] J. Garcia-Ubasart, J.F. Colom, C. Vila, N.G. Hernández, M.B. Roncero, T. Vidal, A new procedure for the hydrophobization of cellulose fibre using laccase and a hydrophobic phenolic compound, Bioresour. Technol. 112 (2012) 341-344. doi:10.1016/j.biortech.2012.02.075.

[29] P. Saastamoinen, M.L. Mattinen, U. Hippi, P. Nousiainen, J. Sipilä, M. Lille, A. Suurnäkki, J. Pere, Laccase aided modification of nanofibrillated cellulose with dodecyl gallate, $\quad$ BioResources. $7 \quad$ (2012) 5749-5770. http://www.scopus.com/inward/record.url?eid=2-s2.084872806205\&partnerID=40\&md5=6304db20947d89271f8f316a3b601c56. 
[30] S. Grönqvist, K. Rantanen, R. Alén, M.-L. Mattinen, J. Buchert, L. Viikari, Laccase-catalysed functionalisation of TMP with tyramine, Holzforschung. 60 (2006) 503-508. http://www.scopus.com/inward/record.url?eid=2-s2.033747430127\&partnerID=40\&md5=f48b27655214ac27db38b92265b9a2c5.

[31] T. Kudanga, E.N. Prasetyo, J. Sipilae, P. Nousiainen, P. Widsten, A. Kandelbauer, G.S. Nyanhongo, G. Guebitz, Laccase-mediated wood surface functionalization., Sect. Title Cellul. Lignin, Pap. Other Wood Prod. 8 (2008) 297-302. doi:10.1002/elsc.200800011.

[32] E. Aracri, J.F. Colom, T. Vidal, Application of laccase-natural mediator systems to sisal pulp: An effective approach to biobleaching or functionalizing pulp fibers?., Bioresour. Technol. 100 (2009) 5911-5916.

[33] A. Suurnäkki, T. Oksanen, M. Orlandi, L. Zoia, C. Canevali, L. Viikari, Factors affecting the activation of pulps with laccase, Enzyme Microb. Technol. 46 (2010) 153-158. doi:10.1016/j.enzmictec.2009.11.009.

[34] O. Cusola, C. Valls, T. Vidal, M.B. Roncero, Rapid functionalisation of cellulosebased materials using a mixture containing laccase activated lauryl gallate and sulfonated lignin, Holzforschung. 68 (2014). doi:10.1515/hf-2013-0128.

[35] O. Cusola, C. Valls, T. Vidal, M.B. Roncero, Conferring antioxidant capacity to cellulose based materials by using enzymatically-modified products, Cellulose. 22 (2015) 2375-2390. doi:10.1007/s10570-015-0668-1.

[36] O. Cusola, C. Valls, T. Vidal, M.B. Roncero, Application of surface enzyme treatments using laccase and a hydrophobic compound to paper-based media, Bioresour. Technol. 131 (2013). doi:10.1016/j.biortech.2012.12.186.

[37] O. Cusola, M.B. Roncero, T. Vidal, O.J. Rojas, A Facile and Green Method to Hydrophobize Films of Cellulose Nanofibrils and Silica by Laccase-Mediated 
Coupling of Nonpolar Colloidal Particles, ChemSusChem. 7 (2014). doi:10.1002/cssc.201402432.

[38] J. Coates, Interpretation of Infrared Spectra, A Practical Approach, in: Encycl. Anal. Chem., John Wiley \& Sons, Ltd, 2000. doi:10.1002/9780470027318.a5606.

[39] M.M. Coleman, D.J. Skrovanek, J. Hu, P.C. Painter, Hydrogen bonding in polymer blends. 1. FTIR studies of urethane-ether blends, Macromolecules. 21 (1988) 5965. doi:10.1021/ma00179a014.

[40] P. Widsten, A. Kandelbauer, Laccase applications in the forest products industry: A review, Enzyme Microb. Technol. $42 \quad$ (2008) 293-307. http://www.scopus.com/inward/record.url?eid=2-s2.039149124135\&partnerID=40\&md5=bce61f9453bbce340a06a32f11707c04.

[41] W.G. Glasser, Lignin, in: J.P. Casey (Ed.), Pulp Pap. Chem. Chem. Technol., John Wiley and Sons Ltd, 1980: p. 39.

[42] V. Tulyathan, R.B. Boulton, V.L. Singleton, Oxygen uptake by gallic acid as a model for similar reactions in wines, J. Agric. Food Chem. 37 (1989) 844-849. http://www.scopus.com/inward/record.url?eid=2-s2.00000411487\&partnerID=40\&md5=f9805df108bb7dcccffd67b7df8d986c.

[43] N. Sathyanarayanan, G. Cannone, L. Gakhar, N. Katagihallimath, R. Sowdhamini, S. Ramaswamy, K.R. Vinothkumar, Molecular basis for metabolite channeling in a ring opening enzyme of the phenylacetate degradation pathway, Nat. Commun. 10 (2019). doi:10.1038/s41467-019-11931-1.

[44] W. Ismail, W.S. El-Sayed, Degradation of phenylacetate by Acinetobacter spp.: Evidence for the phenylacetyl-coenzyme A pathway, Ann. Microbiol. 63 (2013) 1451-1458. doi:10.1007/s13213-013-0608-y.

[45] R. Teufel, C. Gantert, M. Voss, W. Eisenreich, W. Haehnel, G. Fuchs, Studies on 
the mechanism of ring hydrolysis in phenylacetate degradation: A metabolic branching point, J. Biol. Chem. 286 (2011) 11021-11034.

648

649

650

651

652

653

654

655

656

657

658

659

660

661

662

663

664

665

666

667

668

669

670 doi:10.1074/jbc.M110.196667.

[46] J.M. Gess, C.W. Dence, Formation of o- benzoquinones in the reaction of creosol with aqueous chlorine, Tappi. $54 \quad$ (1971) 1114-1121. http://www.scopus.com/inward/record.url?eid=2-s2.00015099803\&partnerID=40\&md5=c5152554ced1e387b0ae2c049125985e.

[47] F. Österberg, K. Lindström, Characterization of the High Molecular Mass Chlorinated Matter in Spent Bleach Liquors (SBL). Part II. Acidic SBL, Holzforsch. - Int. J. Biol. Chem. Phys. Technol. Wood. 39 (2009) 149. doi:10.1515/hfsg.1985.39.3.149.

[48] J. Gierer, F. Imsgard, The Reactions of Lignins With Oxygen and Hydrogen Peroxide in Alkaline Media, (1977).

[49] F. Guillén, C. Muñoz, V. Gómez-Toribio, A.T. Martínez, M. Jesús Martínez, Oxygen Activation during Oxidation of Methoxyhydroquinones by Laccase from Pleurotus eryngii, Appl. Environ. Microbiol. $66 \quad$ (2000) 170-175. doi:10.1128/AEM.66.1.170-175.2000.

[50] J. Gierer, Formation and Involvement of Superoxide (O2--/HO2.) and Hydroxyl $(\mathrm{OH} \cdot)$ Radicals in TCF Bleaching Processes: A Review, Holzforsch. - Int. J. Biol. Chem. Phys. Technol. Wood. 51 (1997) 34. doi:10.1515/hfsg.1997.51.1.34.

[51] M. Friedman, Food browning and its prevention: An overview, J. Agric. Food Chem. 44 (1996) X-653. http://www.scopus.com/inward/record.url?eid=2-s2.02842525944\&partnerID=40\&md5=13c50e98f0b37f81f22a4e327428254f.

[52] S. Bittner, When quinones meet amino acids: Chemical, physical and biological consequences, Amino Acids. $30 \quad$ (2006) 205-224. 
678

679

680

681

682

683

684

685

686

687

688

689

690

691

692

693

694

695

http://www.scopus.com/inward/record.url?eid=2-s2.0-

33646564345\&partnerID=40\&md5=2cc8217fa79d7c69a74ac9c35d5974db.

[53] I. Parveen, M.D. Threadgill, J.M. Moorby, A. Winters, Oxidative Phenols in Forage Crops Containing Polyphenol Oxidase Enzymes, J. Agric. Food Chem. 58 (2010) 1371-1382. doi:10.1021/jf9024294.

[54] I. Kubo, I. Kinst-Hori, Y. Kubo, Y. Yamagiwa, T. Kamikawa, H. Haraguchi, Molecular design of antibrowning agents, J. Agric. Food Chem. 48 (2000) 13931399. http://www.scopus.com/inward/record.url?eid=2-s2.00034016131\&partnerID=40\&md5=624f143d4a3cf7692662e32aa3e855ea.

[55] J.M. Gess, The sizing of paper with rosin and alum at acid pHs, in: J.C. Roberts (Ed.), Pap. Chem., Springer Netherlands, 1995: pp. 120-139. doi:10.1007/978-94011-0605-4_8.

[56] J.C. Roberts, Neutral and alkaline sizing, in: J.C. Roberts (Ed.), Pap. Chem., Blackie \& Son Ltd., Glasgow, 1991: p. 114.

[57] D. Eklund, T. Lindström, Water penetration and internal sizing, in: Pap. Chem. An Introd., DT Paper science publications, Grankulla, Finland, 1991: p. 192.

[58] A. Carlmark, E. Larsson, E. Malmström, Grafting of cellulose by ring-opening polymerisation - A review, Eur. Polym. J. 48 (2012) 1646-1659. doi:10.1016/j.eurpolymj.2012.06.013.

[59] Y. Teramoto, S. Ama, T. Higeshiro, Y. Nishio, Cellulose Acetate-graftPoly(hydroxyalkanoate)s: Synthesis and Dependence of the Thermal Properties on Copolymer Composition, Macromol. Chem. Phys. 205 (2004) 1904-1915. doi:10.1002/macp.200400160.

[60] H. Lönnberg, L. Fogelström, A.S. My Ahmed Said, L. Berglund, E. Malmström, A. Hult, Surface grafting of microfibrillated cellulose with poly( $\varepsilon$-caprolactone $)-$ 
Synthesis and characterization, Eur. Polym. J. 44 (2008) 2991-2997. doi:10.1016/j.eurpolymj.2008.06.023.

[61] H. Lönnberg, Q. Zhou, H. Brumer III, T.T. Teeri, E. Malmström, A. Hult, Grafting of cellulose fibers with poly(e-caprolactone) and poly(L-lactic acid) via ringopening polymerization, Biomacromolecules. 7 (2006) 2178-2185. http://www.scopus.com/inward/record.url?eid=2-s2.033746319530\&partnerID=40\&md5=a7ce618c44feac8d9af443c15bb9306c.

[62] L. Najemi, T. Jeanmaire, A. Zerroukhi, M. Raihane, Organic catalyst for ring opening polymerization of $\varepsilon$-caprolactone in bulk. Route to starch-graftpolycaprolactone, Starch - $\quad$ Stärke. $62 \quad$ (2010) 147-154. doi:10.1002/star.200900198.

[63] C. Thomas, F. Peruch, B. Bibal, Ring-opening polymerization of lactones using supramolecular organocatalysts under simple conditions, RSC Adv. 2 (2012) 12851-12856. doi:10.1039/C2RA22535B.

[64] L. Carlsson, S. Utsel, L. Wagberg, E. Malmstrom, A. Carlmark, Surface-initiated ring-opening polymerization from cellulose model surfaces monitored by a Quartz Crystal Microbalance, Soft Matter. 8 (2012) 512-517. doi:10.1039/C1SM06121F.

[65] J. Hafrén, A. Córdova, Direct Organocatalytic Polymerization from Cellulose Fibers, Macromol. Rapid Commun. $26 \quad$ (2005) 82-86. doi:10.1002/marc.200400470. 
Table 1

720

721

722

723

724

725

726

727

728

729

\begin{tabular}{cc}
\hline Gallate & $\begin{array}{c}\text { Carbonyl } \\
\text { frequency }\end{array}$ \\
\hline GA & $1697 \mathrm{~cm}^{-1}$
\end{tabular}

MG $\quad 1669 \mathrm{~cm}^{-1}$

EG $\quad 1704 \mathrm{~cm}^{-1}$

PG $\quad 1689 \mathrm{~cm}^{-1}$

BG $\quad 1687 \mathrm{~cm}^{-1}$

OG $\quad \begin{gathered}1684 \mathrm{~cm}^{-1} \\ (\text { double })\end{gathered}$

LG $\quad 1666 \mathrm{~cm}^{-1}$

SG $\quad 1668 \mathrm{~cm}^{-1}$

730

731

732

733

734

735

736

737

738

739

740

741

742

743

744 
a
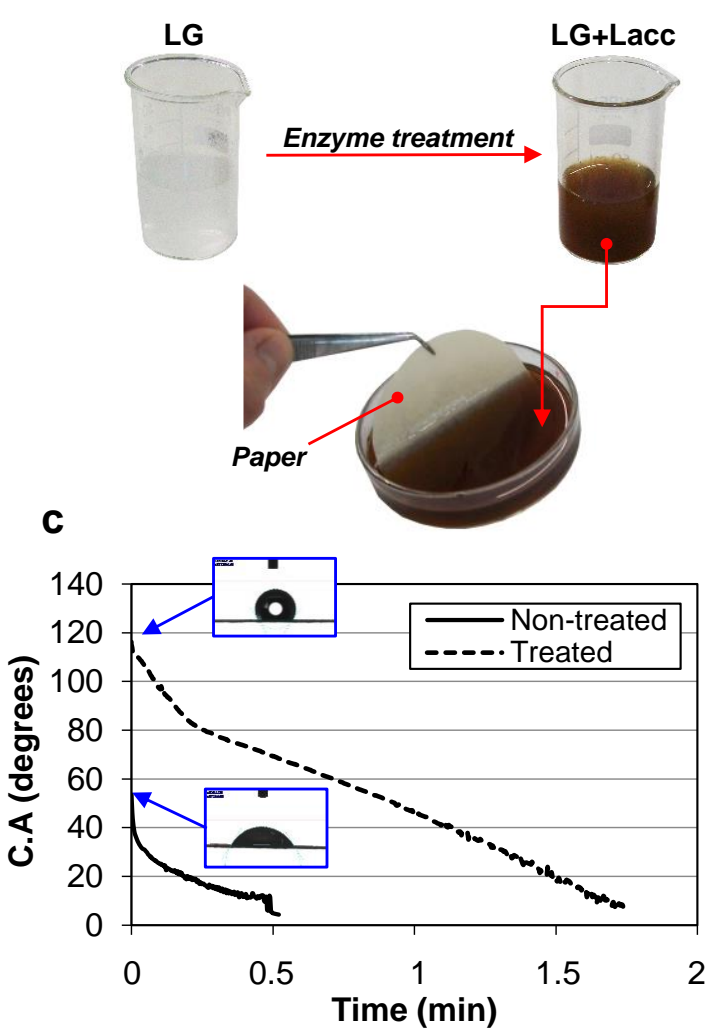

b

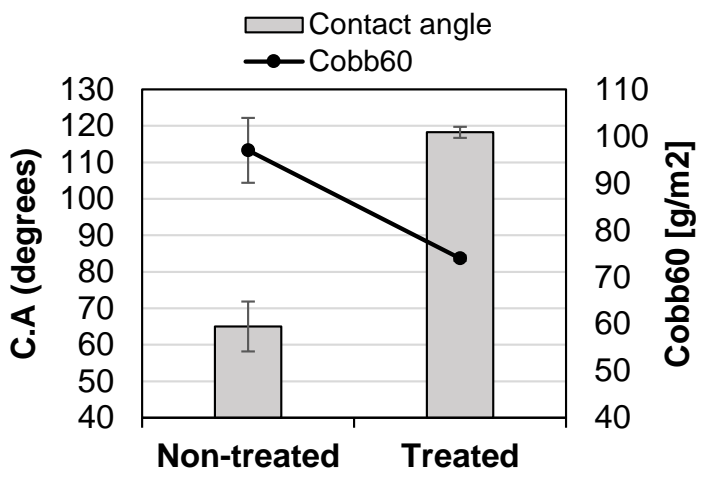

d

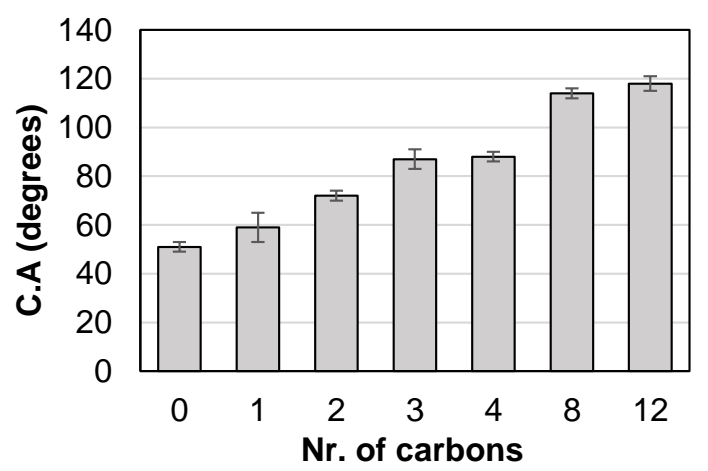



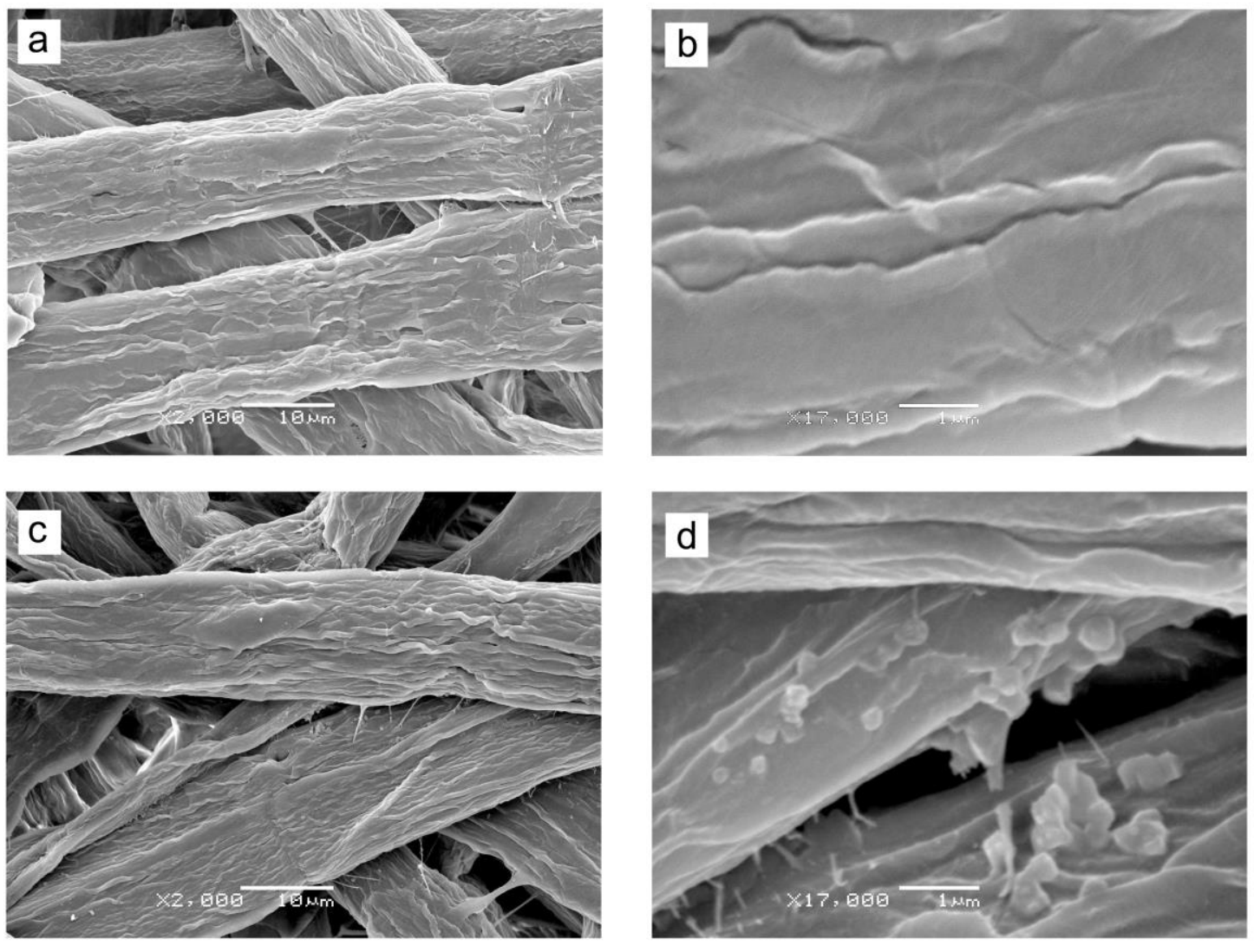

751

Figure 2

752 
754

755

756

757

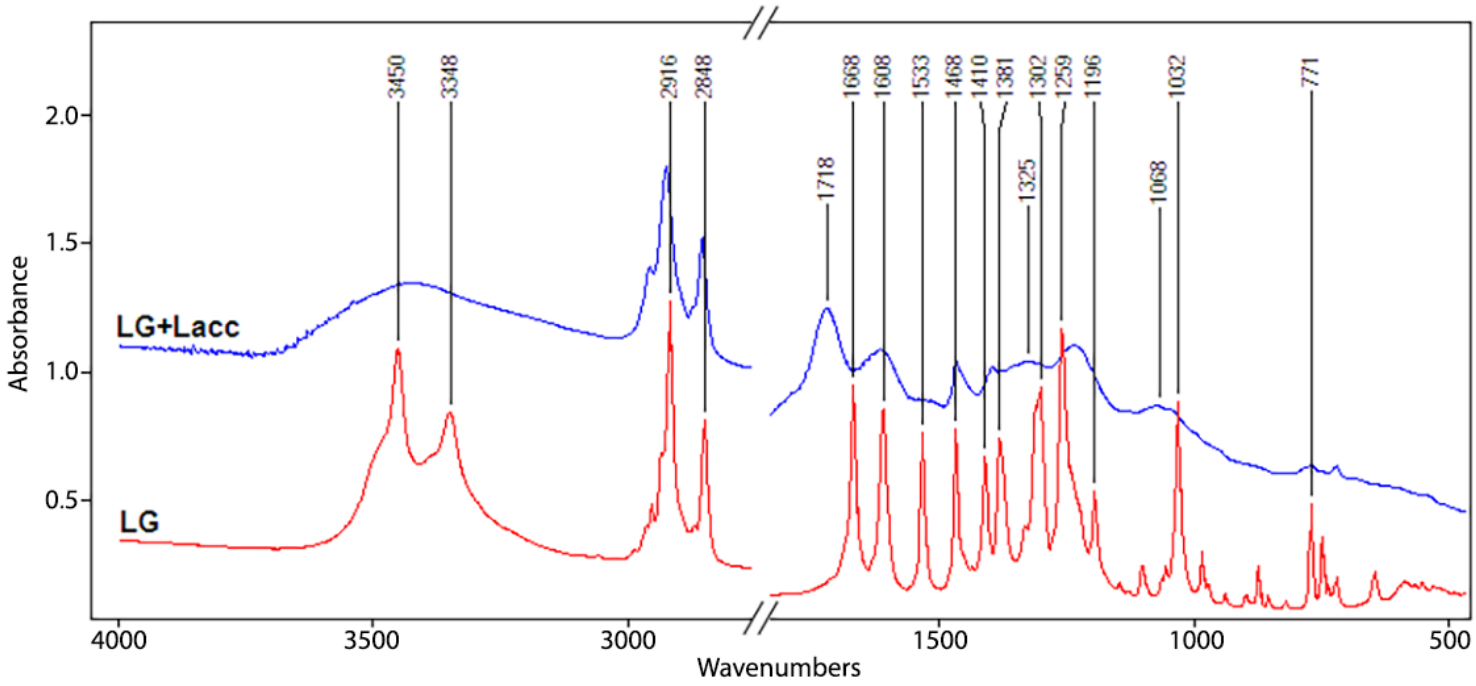

Figure 3

758 
(5)

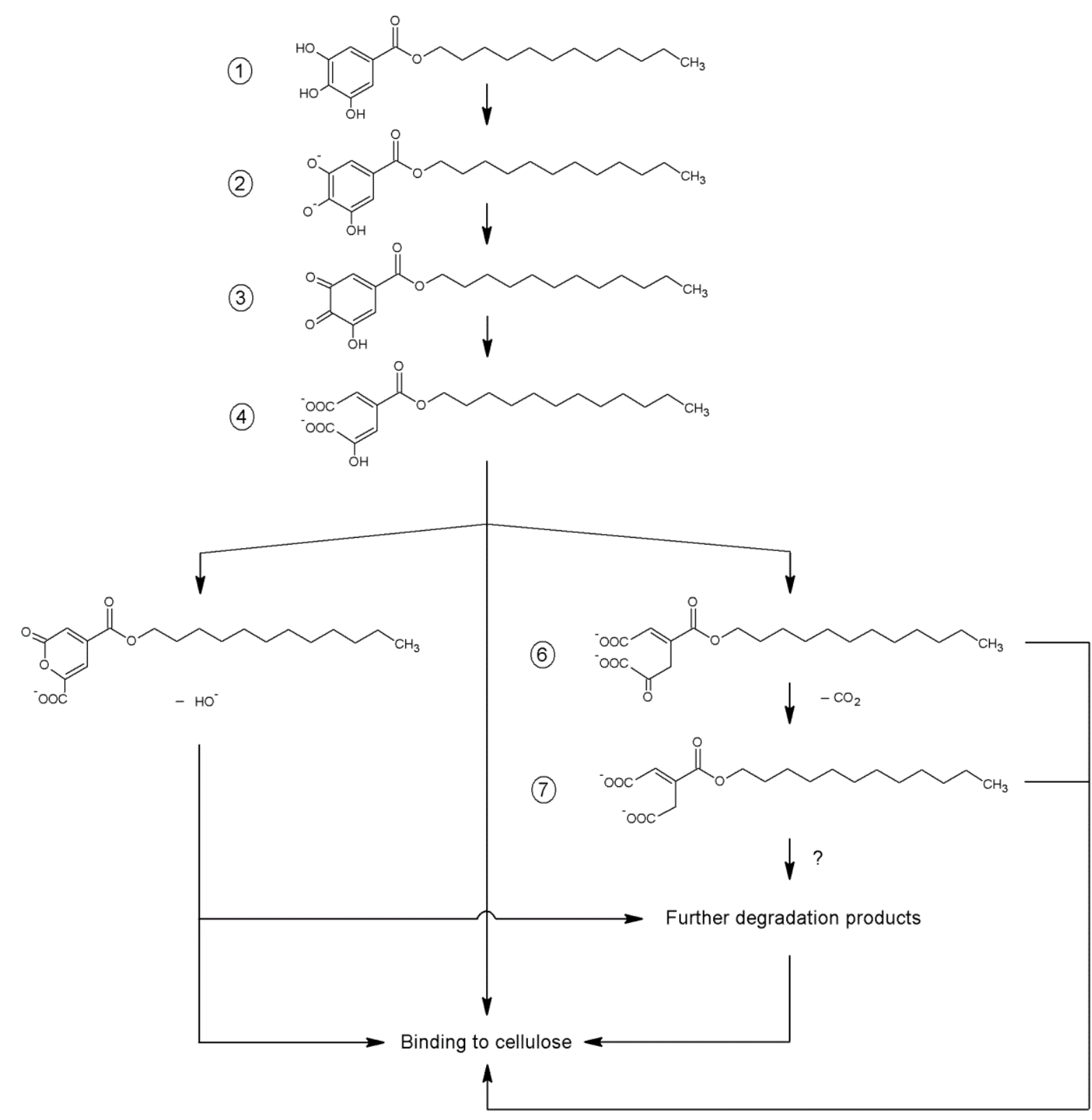

\section{Figure 4}

763

764

765

766 
a

C

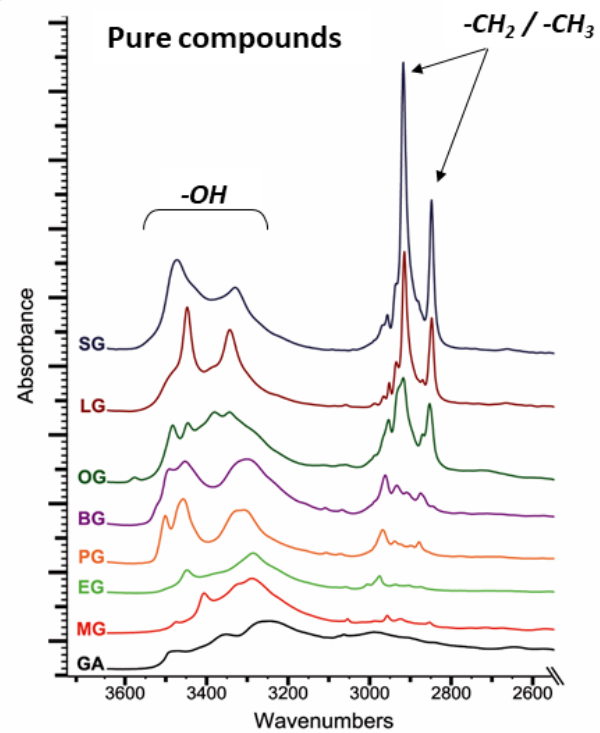

b

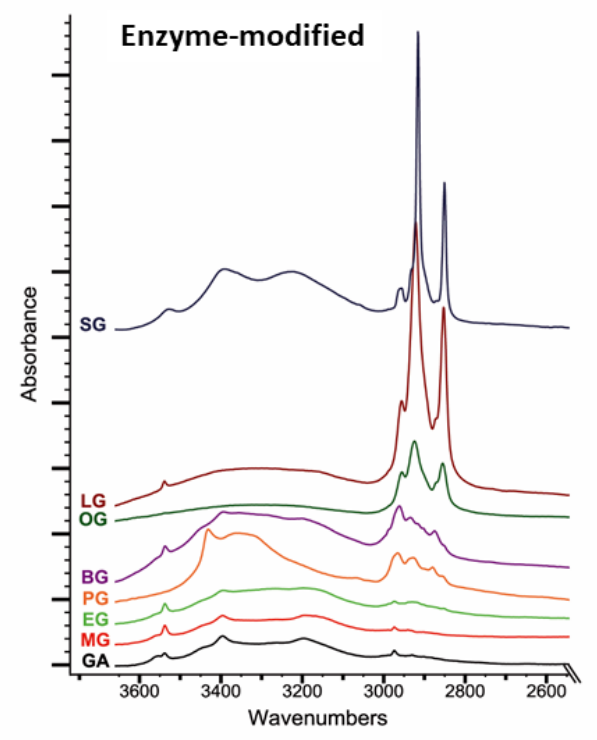

$c=c-c$

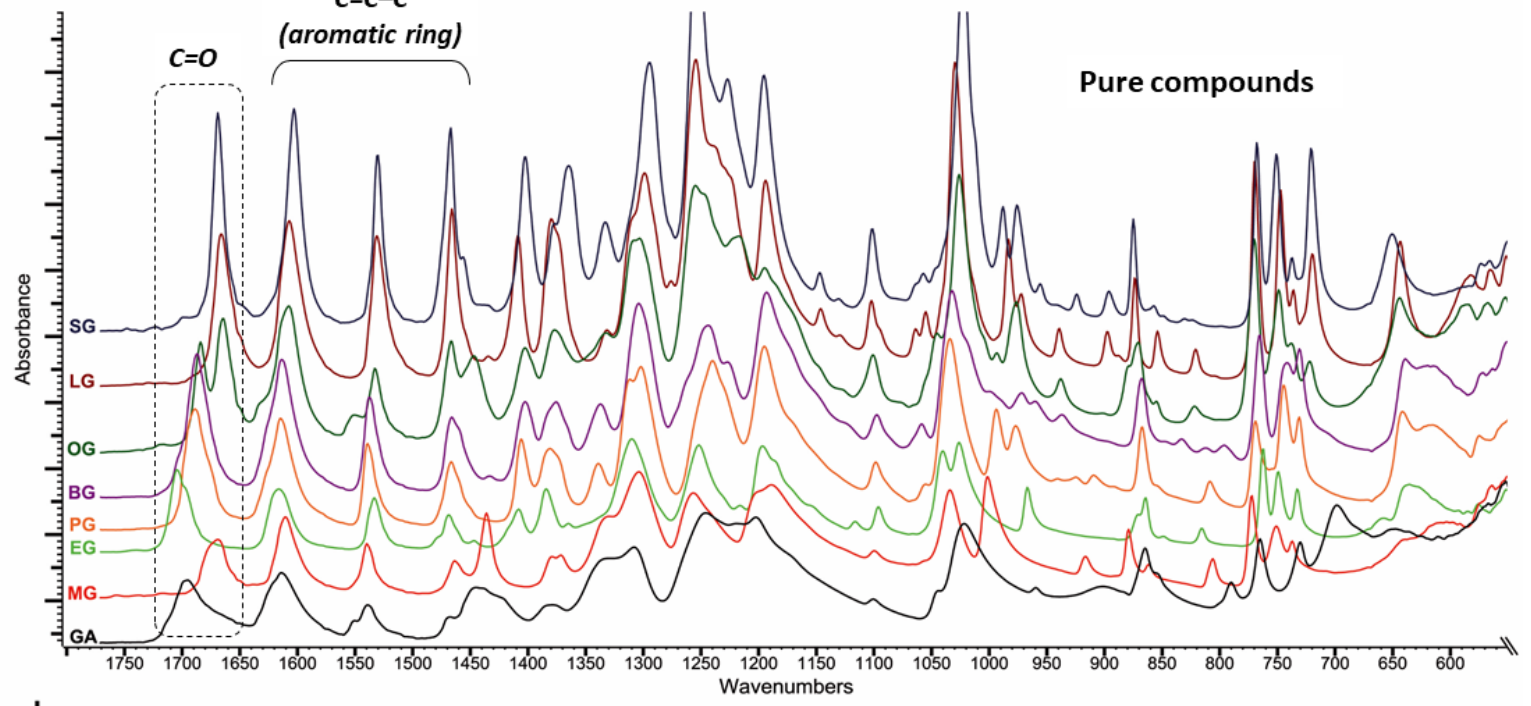

d

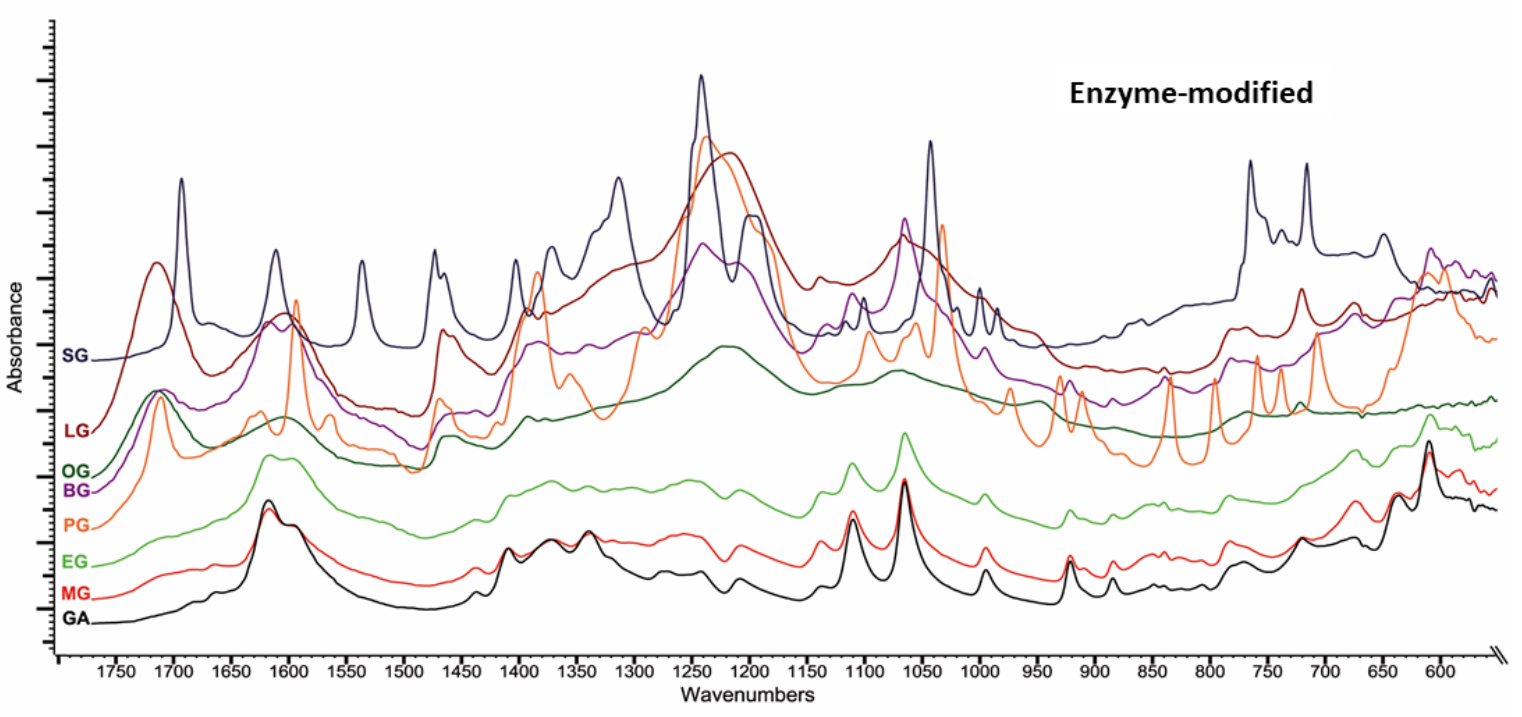




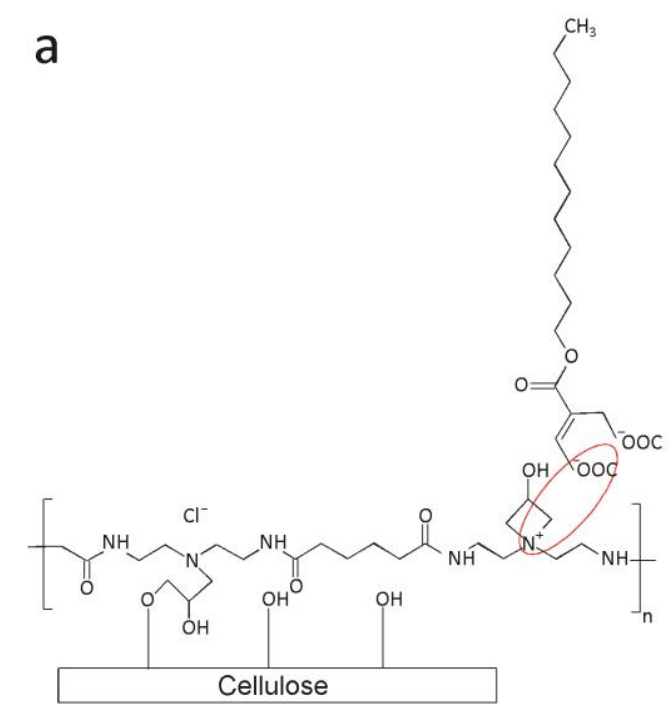

\section{b}
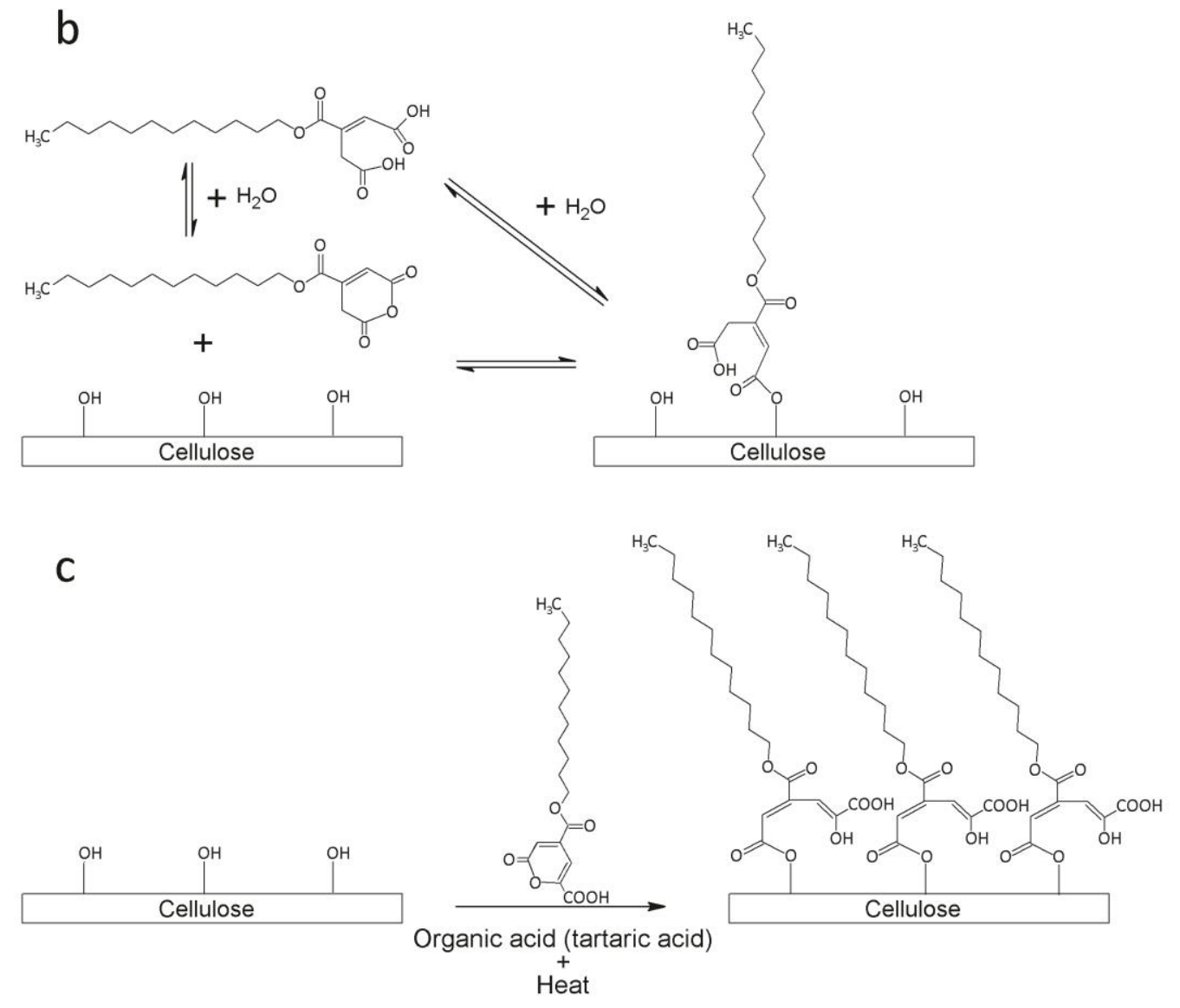

772

\section{Figure 6}

774 
$778 \quad$ List of figure and table captions

779 Figure 1. Aqueous suspensions of LG before and after reaction with laccase, and

780 treatment of paper sheets (a); water contact angle and Cobb $_{60}$ values of a $67 \mathrm{~g} / \mathrm{m} 2$ paper

781 material before and after treatment with FS (b); time-dependent evolution of the water

782 CA of FS-treated and non-treated $67 \mathrm{~g} / \mathrm{m} 2$ papers (c); and hydrophobic behavior

783 evolution of paper sheets trated with enzyme-modified ingreasing alkyl-chain-length

784 gallates (d).

785 Figure 2. SEM images of untreated eucalyptus sheets (a, b), and FS-treated sheets (c, d).

786 The images on the left are macroscopic views of the paper specimens (2000x) and those

787 on the right are close views of the surface of a single fibre $(17,000 x)$.

788 Figure 3. FTIR spectra for the LG before and after modification by the enzyme.

789 Figure 4. Proposed oxidation mechanism for LG.

790 Figure 5. FTIR spectra for pure (a) and enzyme-modified gallates (b) in the range 3600$7912600 \mathrm{~cm}-1$; FTIR spectrum of the pure (a), and enzyme-modified (b) gallates in the 792 wavenumbers ranging from the 1750 to the $600 \mathrm{~cm}-1$.

793 Figure 6. Physico-chemical interaction between PAAE-treated cellulose and an enzyme794 modified LG moiety (a); attachment of enzyme-modified LG moieties to the surface of 795 cellulose via Fischer's esterification reaction and drying (b); and tartaric acid-catalyzed 796 ROP of the enzyme-modified LG lactone from cellulose fibers (c).

797 Table 1. FTIR absorption frequencies for the carbonyl group $(\mathrm{C}=\mathrm{O})$ in the pure gallates. 798 